\title{
Comparison of the functional results of single lung transplantation for pulmonary fibrosis and chronic airway obstruction
}

\author{
R A Chacon, P A Corris, J H Dark, G J Gibson
}

\begin{abstract}
Background - Single lung transplantation (SLT) is now a treatment option for patients with both pulmonary fibrosis and advanced chronic airway obstruction. Lung function after transplantation might be expected to be different in these two groups of patients because of the effect of the remaining native lung, but the implications of these differences have not been fully explored.
\end{abstract}

Methods - The functional results of a stable population of 20 patients ( 13 chronic airway obstruction, seven pulmonary fibrosis) after SLT with no evidence of obliterative bronchiolitis were analysed. The differences between the two populations in the interrelations between and determinants of total lung capacity (TLC), subdivisions of lung volume, airway function (spirometry, maximum expiratory flow volume curves, and moments analysis of the spirogram), respiratory mechanics (PV curves and maximal respiratory pressures), CO transfer factor (TLCO) and the distribution of perfusion, ventilation and volume of the transplanted and native lungs were compared.

Results - Total lung capacity after SLT (TLCpost) was normal in the patients with pulmonary fibrosis (mean (SE) 103.9 (6.9)\% predicted) but remained significantly elevated in patients with airway obstruction (126.4 (4.4)\%). Forced expiratory volume in one second $\left(F E V_{1}\right)$ and vital capacity (VC) improved to similar values after SLT in both groups with a final VC of 76.8 (5.9)\% and 66.7 (3.9)\% in patients with fibrosis and airway obstruction, respectively. Maximum expiratory flows were generally lower and moments analysis of the spirogram showed slower lung emptying with significantly greater second and third moments $\left(\alpha_{2}\right.$ and $\left.\alpha_{3}\right)$ in patients with airway obstruction. Relative ventilation and perfusion of the transplanted lung were both greater in both populations but relative ventilation of the transplanted lung was significantly greater in patients treated for airway disease than in those with pulmonary fibrosis. Tlco was also significantly higher in patients who had received a transplant for chronic airway obstruction.

Conclusions - These results suggest that differences in the functional results of SLT for airway disease and pulmonary fibrosis are relatively minor. In this series the native hyperinflated lung in chronic airway disease was not more disadvantageous to overall function than the native lung in pulmonary fibrosis. However, tests of lung function based on the terminal portion of the forced spirogram are likely to be less sensitive for the detection of obliterative bronchiolitis in patients who have received a transplant for advanced airway obstruction than in those with pulmonary fibrosis.

(Thorax 1998;53:43-49)

Keywords: lung transplantation, pressure-volume curves, moment analysis.

Single lung transplantation (SLT) has been successfully applied in patients with fibrotic lung conditions ${ }^{1-3}$ and, more recently, in patients with advanced chronic airway obstruction. $^{4-11}$ It might be expected that lung function after SLT would be different in the two conditions as the native lung is small and shrunken in patients with pulmonary fibrosis while in those with chronic airway obstruction it is likely to be severely hyperinflated in addition to having airway narrowing. In the early literature concern was expressed that in the latter situation function of the transplanted lung may be compromised by the native lung which might show worsening hyperinflation with time. ${ }^{12-14}$

However, advanced chronic airway obstruction now represents the most common indication for SLT ${ }^{1516}$ and, in contrast to the early experience, recent observations suggest that these patients may have a less complicated perioperative course than those with pulmonary fibrosis. ${ }^{17}$ Furthermore, it appears that both types of patient have a similar outcome in terms of exercise performance ${ }^{18-20}$ which may even be comparable to the exercise capacity of patients after double lung transplantation. ${ }^{2122}$

Despite the increasing number of patients receiving SLT, respiratory mechanics after the procedure are incompletely understood and the functional implications of having a native lung which is either fibrotic or hyperinflated have not been fully explored. We have therefore compared the functional results of SLT in patients in these two groups. In particular, we have examined the factors that determine lung volumes in the two populations and the differences in overall respiratory mechanics, airway 
Table 1 Demographic data and mean (SE) lung volume measurements

\begin{tabular}{|c|c|c|c|c|}
\hline & \multicolumn{2}{|c|}{$\begin{array}{l}\text { Airway obstruction } \\
(n=13)\end{array}$} & \multicolumn{2}{|c|}{$\begin{array}{l}\text { Pulmonary fibrosis } \\
(n=7)\end{array}$} \\
\hline $\mathrm{M}: \mathrm{F}$ & \multirow{4}{*}{\multicolumn{2}{|c|}{$\begin{array}{l}7: 6 \\
11 \mathrm{E}, 1 \mathrm{Ob}, 1 \mathrm{~A} \\
6.80(0.27) \\
5.99(0.34)\end{array}$}} & \multirow{4}{*}{\multicolumn{2}{|c|}{$\begin{array}{l}4: 3 \\
6 \mathrm{~F}, 1 \mathrm{~S} \\
6.42(0.45) \\
5.88(0.50)\end{array}$}} \\
\hline Diagnosis & & & & \\
\hline TLCdon (1) & & & & \\
\hline TLCpred (1) & & & & \\
\hline & Pre & Post & Pre & Post \\
\hline \multicolumn{5}{|l|}{ TLC } \\
\hline litres & $8.79(1.8)$ & $7.55(0.48)$ & $4.38(0.48)$ & $6.01(0.48)$ \\
\hline$\%$ predicted & $148(3.5)$ & $126(4.4)^{* *}$ & $73(7.8)$ & $104(6.9)^{*}$ \\
\hline \multicolumn{5}{|l|}{$\mathrm{FEV}_{1}$} \\
\hline litres & $0.48(0.05)$ & $1.93(0.20)+\dagger$ & $1.28(0.30)$ & $2.28(0.20) \dagger$ \\
\hline litres & $1.82(0.20)$ & $2.65(0.20)+\dagger$ & $1.6(0.30)$ & $3.07(0.30)$ \\
\hline$\%$ predicted & $44.9(4.5)$ & $66.7(3.9)^{* *}$ & $38.5(5.8)$ & $76.8(5.9)^{* *}$ \\
\hline \multicolumn{5}{|l|}{ RV } \\
\hline litres & $6.91(0.4)$ & $4.89(0.50)+\dagger$ & $2.78(0.5)$ & $2.94(0.50)$ \\
\hline$\%$ predicted & 372 (17) & $258(18.8)^{* * * *}$ & $162(32.8)$ & $173(32.3)$ \\
\hline
\end{tabular}

TLCdon=TLC predicted for donor; TLCpred $=$ TLC predicted for recipient; $\mathrm{F}=$ fibrosing alveolitis; $\mathrm{S}=$ sarcoidosis; $\mathrm{E}=$ emphysema; $\mathrm{Ob}=$ obliterative bronchiolitis; $\mathrm{A}=$ asthma

$* \mathrm{p}<0.05, * * \mathrm{p}<0.01,{ }^{* * *} \mathrm{p}<0.001$ compared with pretransplantation values.

$\dagger \mathrm{p}<0.01,+\dagger \mathrm{p}<0.001$ compared with predicted values.

function, and carbon monoxide ( $\mathrm{CO}$ ) uptake, as well as the relative distribution of ventilation and perfusion to the transplanted and native lungs.

\section{Methods}

Twenty patients in whom SLT was performed between August 1988 and November 1993 at the Cardiothoracic Centre, Freeman Hospital, Newcastle upon Tyne were investigated. Seven had undergone SLT because of fibrotic lung conditions and 13 for chronic airway obstruction (mainly emphysema) (table 1). Only one of the latter group had $\alpha_{1}$-antiprotease deficiency. Seven patients received a right transplant and 13 a left transplant. Only patients who had no evidence of post transplantation obliterative bronchiolitis were selected for study.

The surgical procedure and methods of lung preservation, which were uniform throughout the study, have been described previously. ${ }^{23}$ Immunosuppressive treatment comprised cyclosporin A, sufficient to maintain a trough serum level of $350-450 \mathrm{ng} / \mathrm{ml}$ in the first six weeks after transplantation and $150-250 \mathrm{ng} /$ $\mathrm{ml}$ thereafter; prednisolone, initially $0.2 \mathrm{mg} / \mathrm{kg}$ daily and gradually tapered with the aim of discontinuing it at the end of the first year after transplantation; and azathioprine, initially $1.5 \mathrm{mg} / \mathrm{kg}$ and adjusted to maintain the white blood count above $4.0 \times 10^{9} / 1$.

The study was approved by the local ethics committee and patients gave informed written consent.

\section{FUNCTIONAL MEASUREMENTS}

Preoperative lung volumes had been measured during the year before the operation in 18 patients (in the other two they had been obtained more than 24 months preoperatively and these were not included in the analysis). Post transplantation measurements were obtained at least six months after transplantation (mean 19.1 months, range 6-45) and at a time when the patients were free of complications.
Forced expiratory volume in the first second $\left(\mathrm{FEV}_{1}\right)$ and vital capacity (VC) were obtained using either a dry wedge spirometer (Vitalograph Ltd) or by integrating flow measured with a pneumotachograph (Flexiflo Model 407, P K Morgan Ltd, Kent, UK). Maximum expiratory flow-volume curves and moments analysis of the spirogram ${ }^{24}$ were also obtained using a pneumotachograph (Flexiflo Model 407). Lung volumes were measured in a constant volume whole body plethysmograph (P K Morgan Ltd). Measurements of carbon monoxide transfer factor (TLCO) and transfer coefficient (KCO) were made using the single breath method using a "Transfertest Model C" (P K Morgan Ltd). Values were corrected for the haemoglobin concentration.

Pressure-volume (PV) curves were obtained in 11 patients using an oesophageal balloon as previously described ${ }^{25}$ with the subject seated in a variable volume plethysmograph $(\mathrm{J} \mathrm{H}$ Emerson). The patient was asked to perform a sequence of three full inflations and the subsequent expiration was interrupted at the mouthpiece after successive small decrements in volume. For each patient at least five manoeuvres were performed, the data were pooled, and an exponential equation of the form $\mathrm{V}=$ $\mathrm{Vmax}-\mathrm{Ae}^{-\mathrm{KP}}$ was fitted over the volume range from total lung capacity (TLC) to functional residual capacity (FRC). The shape constant $\mathrm{K}$ describes the elastic behaviour of the lungs over the whole volume range and is independent of lung size. ${ }^{26}$ Goodness of fit of the curve was assessed visually and by calculation of $\mathrm{R}^{2}$. A curve was considered satisfactory provided $R^{2}>0.90$ and the curve passed the sign ${ }^{27}$ and runs tests. ${ }^{28}$ Maximal inspiratory and expiratory pressures were measured at the mouth during forceful static efforts at FRC and TLC, respectively.

Ventilation scans were performed in all the recipients following the inhalation of ${ }^{133} \mathrm{Xe}$ in the supine position. Inhalation, equilibrium, and washout views were obtained. Perfusion scans were performed after the intravenous injection of ${ }^{99 \mathrm{~m}}$ Tc macroaggregate. Static views were obtained for quantitation of ventilation and perfusion and results expressed as the proportional uptake by each lung.

Predicted values for TLC, VC, residual volume (RV), FRC, and maximal respiratory pressures were obtained from standard reference values. ${ }^{29}$ Predicted values for $\mathrm{K}$ were based on age. $^{30}$

\section{ANALYSIS OF DATA}

Statistical analysis was performed using Minitab Statistical Software (Minitab Inc, State College, Pennsylvania, USA). Results are expressed as mean (SE). Comparisons between and within groups were made using the Student's $t$ test, a p value of $<0.05$ being considered statistically significant.

The factors determining post transplantation TLC (of both lungs together) were assessed by examining the relationships between TLC after transplantation (TLCpost) and (1) TLC of the recipient before transplantation (TLCpre), (2) 


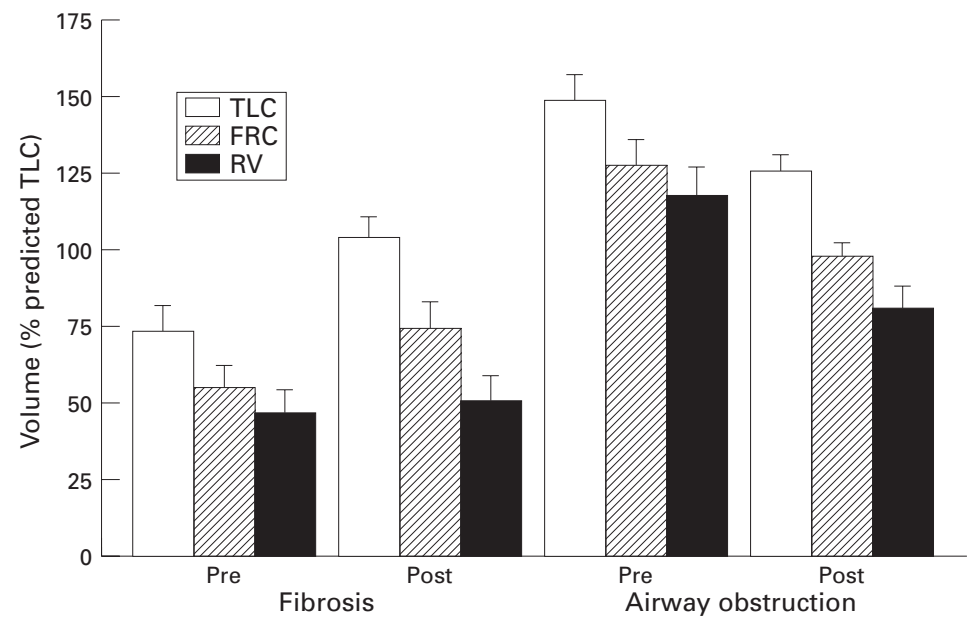

Figure 1 Mean (SE) total lung capacity (TLC), functional residual capacity (FRC) and residual volume $(R V)$ before and after single lung transplantation in both groups of patients.

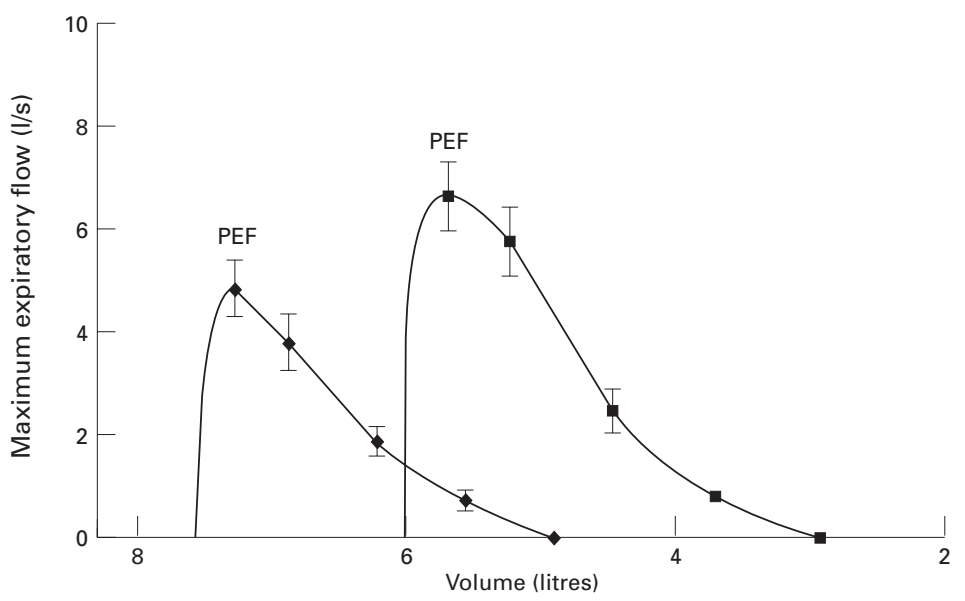

Figure 2 Mean (SE) maximum expiratory flow-volume curves after single lung transplantation for chronic airway obstruction ( $\$$ ) and pulmonary fibrosis ( $\mathbf{\square}$ ). Values represent peak expiratory flow (PEF) and maximum flow at 75\%, 50\%, and $25 \% \mathrm{FVC}$.

TLC predicted for the recipient (TLCpred), and (3) TLC predicted for the donor, calculated from the height and sex of the donor (TLCdon). Both univariate and multiple (stepwise) regression analysis was applied. The height of one donor was unobtainable so it was not possible to calculate TLCdon for this subject.

\section{Results}

LUNG VOLUMES

$T L C$

Measurements of TLC are shown in table 1 and fig 1 for each group of patients with values expressed in litres and as percentages of the recipients' predicted value. Before transplantation the static lung volumes differed as expected with the underlying disease. On average, the patients with airway obstruction had TLC values which were considerably higher than predicted, while in those with fibrotic lung disease TLC was significantly below the predicted values. Postoperatively these values returned towards normal. In the patients with airflow obstruction postoperative TLC was intermediate between the value before transplantation and that predicted for the recipient. In the fibrotic group TLC after transplantation was on average normal. The relative change in TLC in both groups was similar; expressed in relation to the recipients' predicted TLC, there was a mean (SE) increase of 26.8 $(7.7) \%$ in the fibrotic group $(n=6)$ and a reduction of 24.3 (7.3)\% in patients with airway obstruction. In the latter group TLC remained significantly higher than normal after transplantation.

In patients with airway obstruction regression analyses showed strong relations between TLCpost and each of the three potential predictors (TLCpre, TLCpred, TLCdon) individually $\left(\mathrm{R}^{2}=0.62-0.76\right)$. Multiple stepwise regression showed that TLCpost was significantly related to both the recipients' predicted value and to the measured TLC before transplantation $\left(\mathrm{R}^{2}=0.87\right)$. In patients with pulmonary fibrosis the closest correlation was with the recipients' predicted TLC, although this did not reach conventional statistical significance $\left(\mathrm{R}^{2}=47.6, \mathrm{p}=0.086\right)$.

In both groups TLCdon was slightly greater than TLCpred and they were strongly correlated with each other due to the effect of size matching before transplantation.

\section{$F E V_{1}, V C$ and $R V$}

Preoperative VC was reduced to a similar extent in both groups of patients. An increase in VC was seen in both groups after transplantation with final values of 76.8 (5.9)\% and 66.7 (3.9)\% predicted in patients with fibrosis and airway obstruction, respectively.

$\mathrm{FEV}_{1}$ increased by 46.8 (5.3)\% predicted in the group with airway obstruction and by 31.8 (5.13)\% predicted in the fibrotic group, but remained significantly less than predicted in both groups.

There was no significant difference after transplantation between the groups in the $\mathrm{FEV}_{1}$ /VC ratio: 0.73 (0.03) for the group with airway obstruction and $0.75(0.03)$ for the fibrotic group.

RV was increased in both groups before transplantation, and significantly so in patients with airway obstruction. A reduction in RV was seen in the airway obstruction group, but it remained significantly higher than predicted after transplantation (fig 1).

\section{MAXIMAL EXPIRATORY FLOW-VOLUME CURVES} AND MOMENTS ANALYSIS

The overall shape of the maximum flow-volume curve was different between the two groups (fig 2). Peak expiratory flow (PEF) and maximum expiratory flow at $75 \%$ of the vital capacity $\left(\mathrm{MEF}_{75}\right)$ were significantly less in the patients with airway obstruction. Maximum expiratory flow at $50 \%$ and $25 \%$ of the vital capacity $\left(\mathrm{MEF}_{50}\right.$ and $\left.\mathrm{MEF}_{25}\right)$ and maximum mid expiratory flow between $75 \%$ and $25 \%$ of the vital capacity (MMEF) were also lower in the airway obstruction group but the differences 
Table 2 Mean (SE) maximal expiratory flows (\% predicted) and moments analysis of the spirogram

\begin{tabular}{|c|c|c|c|c|c|c|c|c|c|}
\hline & $P E F$ & $M M E F$ & $M E F_{75}$ & $M E F_{50}$ & $M E F_{25}$ & $\begin{array}{l}\alpha_{1} \\
(s)\end{array}$ & $\begin{array}{l}\alpha_{2} \\
\left(s^{2}\right)\end{array}$ & $\begin{array}{l}\alpha_{3} \\
\left(s^{3}\right)\end{array}$ & $\begin{array}{l}\text { Moment } \\
\text { ratio } \\
\left(\sqrt{\alpha_{2}} / \alpha_{1}\right)\end{array}$ \\
\hline Airway obstruction & $\begin{array}{l}64.0 \\
(6.6)\end{array}$ & $\begin{array}{l}44.9 \\
(8.2)\end{array}$ & $\begin{array}{l}57.1 \\
(7.5)\end{array}$ & $\begin{array}{l}43.5 \\
(6.8)\end{array}$ & $\begin{array}{l}39.2 \\
(9.8)\end{array}$ & $\begin{array}{l}0.88 \\
(0.07)\end{array}$ & $\begin{array}{l}1.87 \\
(0.32)\end{array}$ & $\begin{array}{l}6.2 \\
(1.40)\end{array}$ & $\begin{array}{l}1.48 \\
(0.04)\end{array}$ \\
\hline Pulmonary fibrosis & $\begin{array}{l}85.9 \\
(7.6)\end{array}$ & $\begin{array}{l}54.7 \\
(9.0)\end{array}$ & $\begin{array}{l}84.3 \\
(8.2)\end{array}$ & $\begin{array}{l}55.9 \\
(9.0)\end{array}$ & $\begin{array}{l}45.4 \\
(10.2)\end{array}$ & $\begin{array}{l}0.70 \\
(0.06)\end{array}$ & $\begin{array}{l}1.07 \\
(0.17)\end{array}$ & $\begin{array}{l}2.65 \\
(0.79)\end{array}$ & $\begin{array}{l}1.52 \\
(0.03)\end{array}$ \\
\hline $\mathrm{p}$ values & 0.048 & NS & 0.03 & NS & NS & 0.059 & 0.04 & 0.04 & NS \\
\hline
\end{tabular}

$\mathrm{PEF}=$ peak expiratory flow; $\mathrm{MMEF}=$ maximum mid expiratory flow between $75 \%$ and $25 \%$ of vital capacity; $\mathrm{MEF}_{75}, \mathrm{MEF}_{50}$, $\mathrm{MEF}_{25}=$ maximum expiratory flow at $75 \%, 50 \%$ and $25 \%$ of the vital capacity to be expired respectively; NS=non-significant. $\mathrm{p}$ values refer to differences between patient groups.
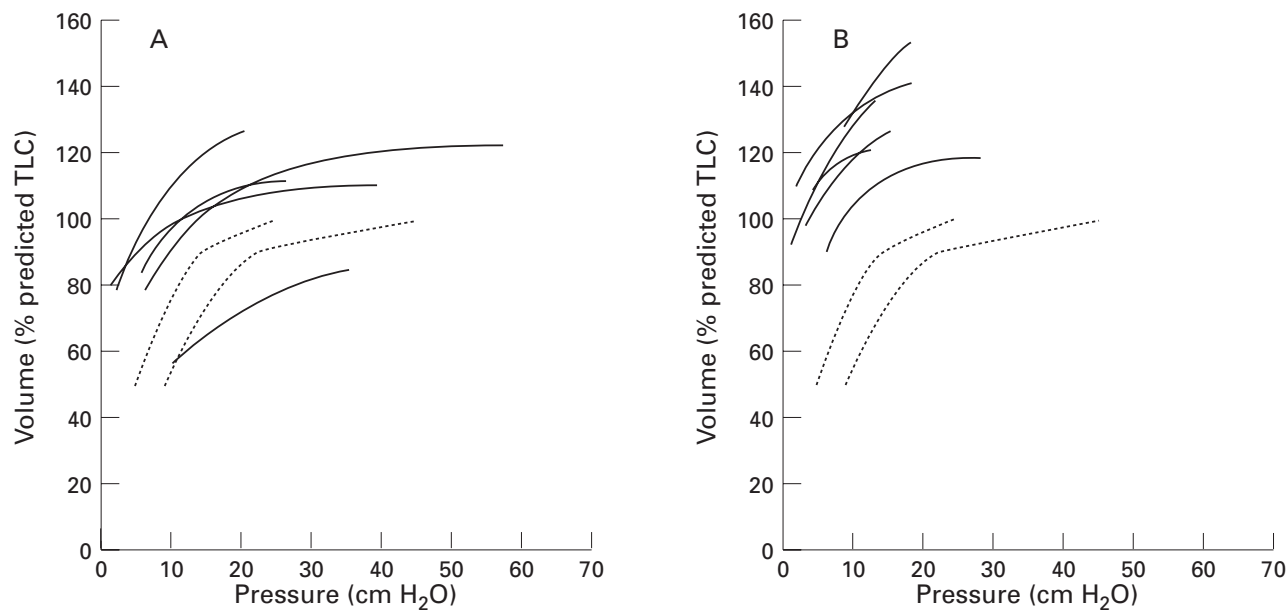

Figure 3 Pressure-volume curves for each patient with $(A)$ pulmonary fibrosis and $(B)$ emphysema. Volume is expressed as $\%$ of predicted TLC for the recipient. Dotted lines are the predicted normal range. ${ }^{31}$

were not statistically significant. Moments analysis of the spirogram about the origin showed significant differences between the two groups in the second and third moments $\left(\alpha_{2}\right.$ and $\left.\alpha_{3}\right)$, corresponding to a more prolonged expiratory time in the patients with airway obstruction (table 2).

\section{PV CURVES AND MAXIMUM RESPIRATORY} PRESSURES

PV curves for patients after transplantation are shown in fig 3 with values of $\mathrm{K}$ and maximum lung recoil pressure (Plmax) summarised in table 3. Although, on average, lung compliance expressed as $\mathrm{K}$ was lower in patients who received an SLT for lung fibrosis, the difference was not significant. Most of the curves were displaced upward on the volume axis compared with the normal range. In accord with their greater TLC, the curves of patients with airway obstruction were more markedly displaced and they reached significantly lower maximal transpulmonary pressures.

Preoperatively Pemax was normal in both groups and it showed no significant change after transplantation. PImax was markedly reduced in patients with airway obstruction compared with normal $(\mathrm{p}=0.0005)$ and became more normal after transplantation.

CARBON MONOXIDE TRANSFER FACTOR

Values of TLCO were greater in the group transplanted because of airway obstruction $(\mathrm{p}=$ 0.018 ) but the difference between the two groups in the transfer coefficient (KCO) was not significant (table 4 ).

\section{VENTILATION PERFUSION SCANS}

The inhalation scans showed predominant ventilation of the transplanted lung in both groups and this was more marked in patients with airway obstruction (table 4, fig 4). After equilibration of the inhaled isotope, however, the relative activity in the transplanted lung was similar in both groups, with the transplanted lungs continuing to show the greater uptake of isotope. In both groups the transplanted lung received most of the perfusion

Table 3 Mean (SE) pressure-volume (PV) curves and maximum respiratory pressures

\begin{tabular}{|c|c|c|c|c|c|c|c|c|}
\hline \multirow[t]{2}{*}{ Group } & \multirow[t]{2}{*}{$n$} & \multicolumn{3}{|c|}{$P V$ curves after transplantation } & \multicolumn{2}{|c|}{$\operatorname{PImax}\left(\mathrm{cmH}_{2} \mathrm{O}\right)$} & \multicolumn{2}{|c|}{ PEmax $\left(\mathrm{cmH}_{2} \mathrm{O}\right)$} \\
\hline & & $\mathrm{K}\left(\mathrm{cmH}_{2} \mathrm{O}\right)$ & $K(\%$ predicted $)$ & $\begin{array}{l}\text { PLmax } \\
\left(\mathrm{cmH}_{2} \mathrm{O}\right)\end{array}$ & Pre & Post & Pre & Post \\
\hline Airway obstruction & 6 & $0.131(0.025)$ & $91.3(17.7)$ & $17.4(2.33) \dagger$ & *34.8 (5.6) $\ddagger$ & $70.7(11.2) \ddagger$ & *96.6 (17.8) & $97.3(14.4)$ \\
\hline Pulmonary fibrosis & 5 & $0.099(0.015)$ & $72.6(11.7)$ & $35.4(6.35) \dagger$ & $66.4(13.6)$ & $73.0(9.6)$ & $104(4.5)$ & $95.8(10.8)$ \\
\hline
\end{tabular}

PLmax $=$ maximum lung recoil pressure; PImax, PEmax $=$ maximum inspiratory and expiratory pressure.

$* \mathrm{n}=5$.

†, $\neq \mathrm{p}<0.05$ 
Table 4 Mean (SE) relative ventilation and perfusion of the transplanted lung (\% of total) and $\mathrm{CO}$ transfer (\% predicted)

\begin{tabular}{llllll}
\hline & \multicolumn{1}{l}{ Ventilation } & Perfusion & \multirow{2}{*}{ TLCO } & \multirow{2}{*}{ KCO } \\
\cline { 2 - 4 } & Inhalation & Equilibrium & & & \\
\hline $\begin{array}{l}\text { Airway } \\
\text { obstruction }\end{array}$ & $83.2(2.5)$ & $57.7(2.2)$ & $77.3(4.5)$ & $76.0(4.5)$ & $113.3(5.0)$ \\
$\begin{array}{l}\text { Pulmonary } \\
\text { fibrosis }\end{array}$ & $65.9(4.9)$ & $56.1(2.6)$ & $74.3(3.1)$ & $59.7(4.24)$ & $94.0(10.1)$ \\
p values & 0.011 & NS & NS & 0.018 & NS \\
\hline
\end{tabular}

$\mathrm{NS}=$ non-significant

$\mathrm{p}$ values refer to differences between patient groups.

and its relative distribution was similar in the two groups.

\section{Discussion}

Our data suggest that patients with advanced chronic airway obstruction and pulmonary fibrosis show overall improvements of similar magnitude following SLT, but there were subtle differences between the two groups.

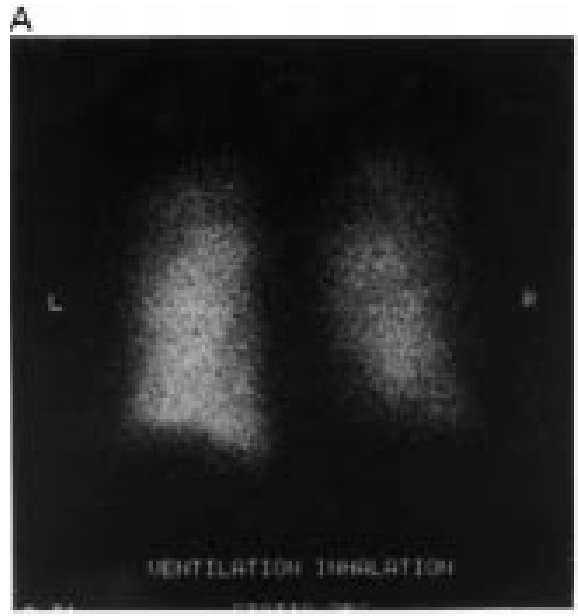

Wentilstion

Left $59 \%$ Right $41 \%$

B

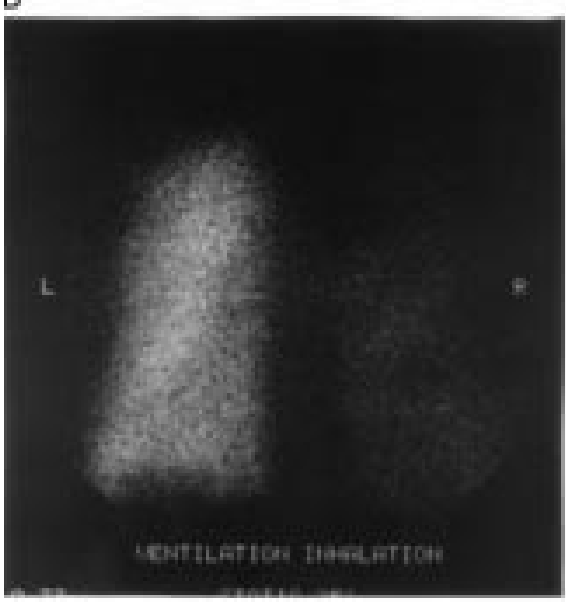

Wentilation

Left $80 \%$ Right $20 \%$
In both groups lung volumes of the two lungs returned towards normal. The patients with airway obstruction had severe hyperinflation before transplantation and a moderate degree of hyperinflation remained due to the presence of the native lung. In both groups the main determinant of post transplantation TLC appeared to be the predicted TLC of the recipient, suggesting that in both groups the chest wall adapts to the volume of the transplanted lung. Additionally, in patients with airway obstruction the TLC before transplantation influenced the final TLC after transplantation, reflecting continued hyperinflation of the native lung. The changes in TLC after transplantation in this population were of similar magnitude to those reported previously. ${ }^{17}$

In keeping with previous reports ${ }^{10} 18$ the data from the ventilation scans showed preferential ventilation of the transplanted lung during a single inhalation of isotope. Contrary to earlier fears that a hyperinflated native lung would

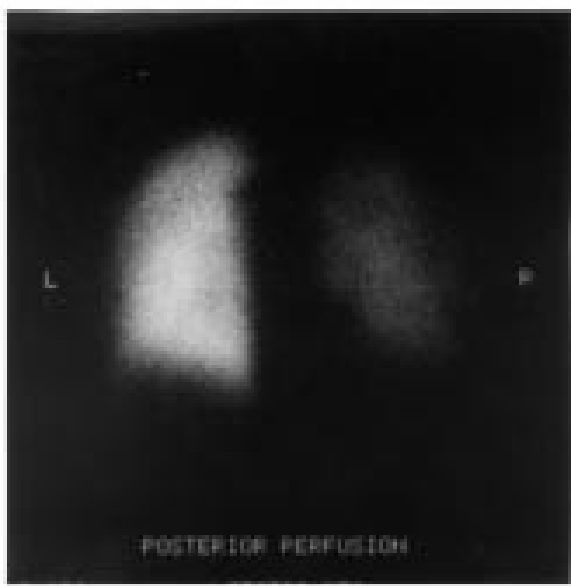

Perfusion

Left $78 \%$ Right $22 \%$

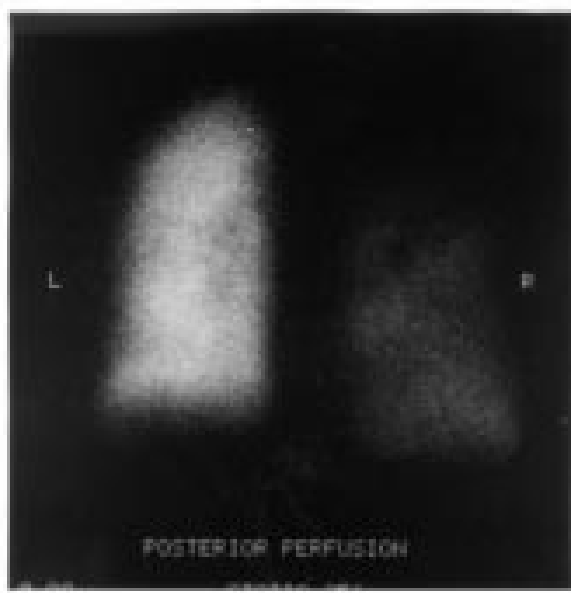

Perfusion

Left $76 \%$ Right $24 \%$

Figure 2 Ventilation and perfusion scans following transplantation in (A) a patient with left single lung transplantation for pulmonary fibrosis and (B) a patient with left single lung transplantation for emphysema. Posterior views, $\%$ of total uptake of isotope. Note that relative ventilation of the native lung in the patient with emphysema is less than in pulmonary fibrosis, whereas the relative distribution of perfusion is similar in both. 
interfere with ventilation of the transplanted lung, our data showed that the relative ventilation of the transplanted lung in patients with preoperative airway obstruction was actually greater than in fibrosis. The carbon monoxide transfer factor was also higher in patients with airway obstruction, probably because of the better ventilation of the transplanted lung compared with patients with lung fibrosis.

Distribution of the radioactive isotope after equilibration, although more even, was still preferential to the transplanted lung. In both groups of patients the transplanted lung received approximately three quarters of the total perfusion. These results therefore suggest that the native lung does not interfere importantly with the function of the transplanted lung in either group.

The effect of the native lung on overall airway function was evident on examination of the MEFV curves and moments analysis of the forced expiratory spirogram. Patients who had received SLT for end-stage airway obstruction had generally lower maximum expiratory flows compared with patients with lung fibrosis. This is likely to be due to both a reduced driving (lung recoil) pressure and to the effect of residual airway narrowing in the native lung in this group. Although the ventilation scans indicated little ventilation of the native hyperinflated lung, its effect is likely to become more evident towards the end of expiration when emptying of the normal transplanted lung is virtually complete. The effect of such slow emptying, albeit of a poorly ventilated lung, is emphasised by moments analysis of the spirogram which gives information in the time rather than the volume domain.

The first moment about the origin $\left(\alpha_{1}\right)^{24}$ was non-significantly greater in patients after transplantation for chronic airway obstruction than in the fibrotic group; with the second and third moments $\left(\alpha_{2}\right.$ and $\left.\alpha_{3}\right)$ the difference became more apparent. Moments analysis of the spirogram has the theoretical advantage over the conventional parameters derived from the flow-volume curve of giving information which is not limited to a specific part of expiration. Each moment is calculated from the relation of time and volume throughout the entire expiration and is dependent on the time of expiration (and therefore is influenced particularly by slowly emptying units). The first moment, otherwise known as the mean transit time (MTT), gives an estimate of the mean time of expiration. With the higher moments, increasingly greater emphasis is given to the terminal portion of expiration and to the slowest emptying units.

The overall pressure-volume curves of the lungs were different in the two populations. Patients with airway obstruction showed a shift of the PV curve to higher volumes and lower transpulmonary pressures compared with the fibrotic group. This is attributable to the influence of the hyperinflated native lung in the group with airway obstruction; since it is little ventilated it contributes to the volume axis, largely as "dead space", without significantly affecting the overall compliance $(\mathrm{K})$. On the other hand, in the patients with pulmonary fibrosis the native lung received relatively more ventilation which probably accounts for the generally lower $\mathrm{K}$ values.

In summary, our results show that there are differences in terms of static lung volumes, maximum expiratory flow, and relative ventilation between the two groups but suggest that the overall functional outcome of SLT for chronic airway obstruction is comparable to the results of the longer established SLT for pulmonary fibrosis. The data therefore do not suggest a particular disadvantage for patients who receive a lung transplant because of endstage chronic airway obstruction.

One previous report suggested that the transplanted lung might be significantly restricted after SLT for chronic obstructive pulmonary disease $^{32}$ but in our series patients who had undergone SLT for chronic airway obstruction achieved similar vital capacities to those with pulmonary fibrosis.

Tests of lung function are among the main tools used for the detection of complications such as obliterative bronchiolitis following transplantation $^{33} 34$ and, in particular, special emphasis is given to the final part of expiration. The small but still detectable contribution of the native lung to overall function shown by our studies implies that, as previously suggested, ${ }^{35}$ such tests are likely to be less sensitive in identifying these complications in patients who have undergone SLT for airway disease than for other indications.

The authors thank Mr T N Stone for technical assistance. RAC was in receipt of a training fellowship from the Overseas Development Administration of the British Government in cooperation with the Costa Rican Government.

1 Toronto Lung Transplant Group. Unilateral lung transplantation for pulmonary fibrosis. N Engl f Med 1986; 314:1140-5.

2 Toronto Lung Transplant Group. Experience with singlelung transplantation for pulmonary fibrosis. $\mathscr{f} A M A 1988$ 259:2258-62

3 Grossman RF, Frost A, Zamel N, et al. Results of singlelung transplantation for bilateral pulmonary fibrosis. $N$ Engl 7 Med 1990;322:727-33.

$4 \mathrm{Mal} \mathrm{H}$, Andreassian B, Pamela F, et al. Unilateral lung transplantation in end-stage pulmonary emphysema. $\mathrm{Am}$ Rev Respir Dis 1989;140:797-802.

5 Trulock E, Egan T, Kouchoukos N, et al. Single lung transplantation for severe chronic obstructive pulmonary disease. Chest 1989;96:738-42.

6 Patterson GA, Maurer JR, Williams TJ, Cardoso PG, Scavuzzo $M$, Todd TR. Comparison of outcomes of double and single lung transplantation for obstructive lung disease. The Toronto Lung Transplant Group. I Thorac Cardiovasc Surg 1991;101:623-31; discussion 631-2.

7 Kaiser LR, Cooper JD, Trulock EP, Pasque MK, Triantafillou A, Haydock D. The evolution of single lung transplantation for emphysema. The Washington University Lung Transplant Group. F Thorac Cardiovasc Sur 1991;102:333-9; discussion 339-41.

8 Marinelli WA, Hertz MI, Shumway SJ, et al. Single lung transplantation for severe emphysema. F Heart Lung Transplant 1992;11:577-82; discussion 582-3.

9 Mal H, Sleiman C, Jebrak G, et al. Functional results of single-lung transplantation for chronic obstructive lung
disease. Am 7 Respir Crit Care Med 1994;149:1476-81.

10 Brunsting LA, Lupinetti FM, Cascade PN, et al. Pulmonary function in single lung transplantation for chronic obfunction in single lung transplantation for chronic ob-
structive pulmonary disease. $₹$ Thorac Cardiovasc Surg structive pulmonary disease. F Thorac
1994;107:1337-44; discussion 1344-5.

11 Levine SM, Anzueto A, Peters JI, et al. Medium term functional results of single-lung transplantation for endstage obstructive lung disease. Am $\mathcal{F}$ Respir Crit Care Med 1994;150:398-402.

12 Bates D. The other lung. N Engl f Med 1970;282:277-9. 3 Stevens P, Johnson P, Bell R, Beall A, Jenkins D. Regional ventilation and perfusion after lung transplantation. $N$ Engl f Med 1970;282:245-9.

14 Wildevuur C, Benfield J. A review of 23 human lung transplantations by 20 surgeons. Ann Thorac Surg 1970;9: 489-515. 
15 Low DE, Trulock EP, Kaiser LR, et al. Morbidity, mortality, and early results of single versus bilateral lung transplantation for emphysema. F Thorac Cardiovasc Surg 1992; 103:1119-26.

16 Trulock E. Lung transplantation. Annu Rev Med 1992;43: $1-8$

17 Davis RD Jr, Trulock EP, Manley J, et al. Differences in early results after single-lung transplantation. Washington University Lung Transplant Group. Ann Thorac Surg 1994;58:1327-34; discussion 1334-5.

18 Gibbons WJ, Levine SM, Bryan CL, et al. Cardiopulmonary exercise responses after single lung transplantation for severe obstructive lung disease. Chest 1991;100:106-11.

19 Levy RD, Ernst P, Levine SM, et al. Exercise performance after lung transplantation. F Heart Lung Transplant 1993; 12:27-33.

20 Orens JB, Becker FS, Lynch JP, Christensen PJ, Deeb GM, Martinez FJ. Cardiopulmonary exercise testing following allogeneic lung transplantation for different underlying disease states. Chest 1995;107:144-9.

21 Miyoshi S, Trulock E, Schaefers H, Hsieh C, Patterson G, Cooper J. Cardiopulmonary exercise testing after single
and double lung transplantation. Chest 1990;97:1130-6.

22 Williams TJ, Patterson GA, McClean PA, Zamel N, Maurer JR. Maximal exercise testing in single and double lung transplant recipients. Am Rev Respir Dis 1992;145:101-5.

23 Kirk AJB, Richens D, Dark JH. A manual of cardiopulmonary transplantation. 1st ed. London: Edward Arnold, 1993.

24 Permutt S, Menkes HA. Spirometry. Analysis of forced expiration within the time domain. In: Macklem PT, Permutt S, eds. The lung in the transition between health and disease. New York: Marcel Dekker, 1979:113-52.

25 Gibson GJ, Pride NB. Lung distensibility. The static pressure-volume curve of the lungs and its use in clinical assessment. Br $\mathcal{F}$ Dis Chest 1976;70:43-184.
26 Gibson GJ, Pride NB, Davis J, Schroter RC. Exponential description of the static pressure-volume curve of norma and diseased lungs. Am Rev Respir Dis 1979;120:799-811. 27 Armitage P, Berry G. Statistical methods in medical research 3rd ed. Oxford: Blackwell Scientific Publications, 1994.

28 Draper NR, Smith H. Applied regression analysis. New York: John Wiley and Sons, 1966.

29 European Community for Steel and Coal. Standardised lung function testing. Official Statement of the European Respiratory Society. Eur Respir f 1993;6(Suppl 16):53-83. 30 Colebatch HJH, Greaves IA, Ng CKY. Exponential analysis of elastic recoil and ageing in healthy males and females. f Appl Physiol 1979;47:683-91.

31 Knudson RJ, Clark DF, Kennedy TC, Knudson DE. Effect of ageing alone on mechanical properties of the norma adult human lung. F Appl Physiol 1977;43:1054-62.

32 Cheriyan AF, Garrity ER Jr, Pifarre R, Fahey PJ, Walsh JM. Reduced transplant lung volumes after single lung transplantation for chronic obstructive pulmo

33 Ross D, Belman M, Mohsenifar Z, Nathan S, Kass R, Koerner S. Obstructive flow-volume loop contours after single lung transplantation. F Heart Lung Transplant 1994; 13:508-13.

34 Cooper J, Billingham M, Egan T, et al for the Internationa Society for Heart and Lung Transplantation. A workin formulation for the standardisation of nomenclature and for clinical staging of chronic dysfunction in lung allografts. F Heart Lung Transplant 1993;12:713-6.

35 Becker FS, Martinez FJ, Brunsting LA, Deeb GM, Flint A, Lynch JPR. Limitations of spirometry in detecting rejection after single-lung transplantation. Am $\mathcal{F}$ Respir Crit Care Med 1994;150:159-66. 


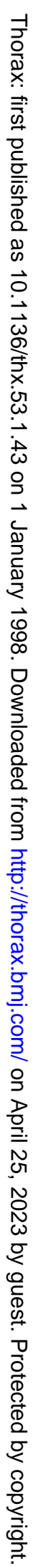

